\title{
Article
}

\section{Predicting the Exception-CRP and Primary Hip Arthroplasty}

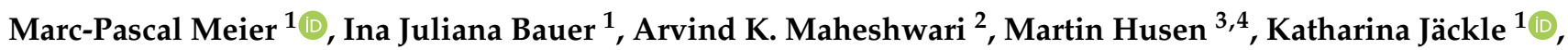 \\ Jan Hubert ${ }^{5}{ }^{\circledR}$, Thelonius Hawellek ${ }^{1}$, Wolfgang Lehmann ${ }^{1}$ and Dominik Saul ${ }^{1,2, *(0)}$
}

1 Department of Trauma, Orthopedics and Reconstructive Surgery, Georg-August-University of Goettingen, 37075 Göttingen, Germany; marc-pascal.meier@med.uni-goettingen.de (M.-P.M.); inajuliana.bauer@stud.uni-goettingen.de (I.J.B.); katharina.jaeckle@med.uni-goettingen.de (K.J.); Thelonius.hawellek@med.uni-goettingen.de (T.H.); Wolfgang.Lehmann@med.uni-goettingen.de (W.L.)

2 Kogod Center on Aging and Division of Endocrinology, Mayo Clinic, Rochester, MN 55905, USA; Maheshwari.Arvind@mayo.edu

3 Department of Orthopedic Surgery, Rochester, MN 55905, USA; Husen.Martin@mayo.edu

4 Department of Trauma, Hand and Reconstructive Surgery, University Hospital Essen, 45147 Essen, Germany

5 Division of Orthopaedics, Department of Trauma and Orthopaedic Surgery, University Medical Center Hamburg-Eppendorf, 20521 Hamburg, Germany; j.hubert@uke.de

* Correspondence: Dominik.Saul@med.uni-goettingen.de; Tel.: +49-551-3922462; Fax: +49-551-398787

\section{check for} updates

Citation: Meier, M.-P.; Bauer, I.J.; Maheshwari, A.K.; Husen, M.; Jäckle, K.; Hubert, J.; Hawellek, T.; Lehmann, W.; Saul, D. Predicting the Exception-CRP and Primary Hip Arthroplasty. J. Clin. Med. 2021, 10, 4985. https://doi.org/10.3390/ jcm10214985

Received: 14 September 2021

Accepted: 26 October 2021

Published: 27 October 2021

Publisher's Note: MDPI stays neutral with regard to jurisdictional claims in published maps and institutional affiliations.

\begin{abstract}
Background: While primary hip arthroplasty is the most common operative procedure in orthopedic surgery, a periprosthetic joint infection is its most severe complication. Early detection and prediction are crucial. In this study, we aimed to determine the value of postoperative C-reactive protein (CRP) and develop a formula to predict this rare, but devastating complication. Methods: We retrospectively evaluated 708 patients with primary hip arthroplasty. CRP, white blood cell count (WBC), and several patient characteristics were assessed for 20 days following the operative procedure. Results: Eight patients suffered an early acute periprosthetic infection. The maximum CRP predicted an infection with a sensitivity and specificity of $75 \%$ and $56.9 \%$, respectively, while a binary logistic regression reached values of $75 \%$ and $80 \%$. A multinominal logistic regression, however, was able to predict an early infection with a sensitivity and specificity of $87.5 \%$ and $78.9 \%$. With a one-phase decay, $71.6 \%$ of the postoperative CRP-variance could be predicted. Conclusion: To predict early acute periprosthetic joint infection after primary hip arthroplasty, a multinominal logistic regression is the most promising approach. Including five parameters, an early infection can be predicted on day 5 after the operative procedure with $87.5 \%$ sensitivity, while it can be excluded with $78.9 \%$ specificity.
\end{abstract}

Keywords: C-reactive protein; CRP; primary hip arthroplasty; orthopedic surgery; revision surgery; periprosthetic joint infection

\section{Highlights}

- $\quad$ Seven hundred and eight patients over four years with a primary hip arthroplasty were retrospectively evaluated.

- On days 11 and 14 post operation, the CRP values were higher in the group with an early infection.

- As a single parameter, maximum CRP predicts an early infection with $75 \%$ sensitivity.

- A multinominal logistic regression can predict an early infection with a sensitivity and specificity of $87.50 \%$ and $78.85 \%$, respectively.

- This is the first mathematical prediction of early acute periprosthetic infection in primary hip arthroplasty.

\section{Introduction}

Germany is the country with the highest rate of hip replacement surgery within the Organization for Economic Co-operation and Development (OECD). With an incidence of 309 per 100,000 in 2017 and a total number of 243,477 procedures (OPS 5-820) in the 
year 2019, it ranges in front of Switzerland and Austria [1]. This number is expected to grow further in future decades with the baby boomer generation reaching the age of 65 in $2021[2,3]$.

The most relevant complication after primary hip arthroplasty is a periprosthetic joint infection (PJI); these infections also represent the second most frequent postoperative complication in Germany $[4,5]$. In combination with individual comorbidities and the need for revision surgeries, PJI significantly increases mortality and morbidity [6-8]. If a PJI of the hip joint occurs in the first postoperative year, the mortality rate is estimated at around $13.6 \%[9,10]$. In addition to mortality and morbidity, another important aspect of PJIs is the increase in healthcare expenditures. According to United States Nationwide Inpatient Sample (NIS) data, the estimated hospital costs for treating a hip PJI were about USD 30,000 and the average total costs for hip revision surgery due to infection were about USD 80,000 [11,12].

Subsequently, it is crucial to determine a potentially infectious complication early [13]. According to the new PJI-TNM classification published in 2021, early infection is equivalent to stage TONOMx. This PJI-TNM classification takes into account implant type and stability, soft tissue conditions, biofilm maturity, pathogen type, patient comorbidities and infection recurrence, overcoming previous classification shortcomings of not capturing PJI diversity $[14,15]$.

To detect an immediate postoperative infection, a thorough clinical wound inspection, regular body temperature measurement and blood tests are generally used. The latter usually include the serum white blood cell count (WBC) and the concentration of C-reactive protein (CRP). The prognostic value of $\mathrm{WBC}$ has been demonstrated to be questionable in an aging cohort $[16,17]$, and lack of availability as well as high costs may preclude the broad use of novel markers like interleukin 6 (IL-6) or procalcitonin (PCT).

According to current knowledge, PJIs cannot be detected based on individual CRP values or the WBC [18]. However, to the authors' knowledge, no study has characterized postoperative CRP kinetics after primary hip arthroplasty and investigated possible correlations with a PJI in the "early stage". The definition of an early PJI can be traced back to Conventry [19]. It was modified continuously, including by, among others, Tsukayama [20]. However, the time span of a PJI varies greatly between 2 and 12 weeks depending on the definition applied [21]. The definition of an early or late PJI more importantly relies on the degree of maturity of the biofilm. In Germany, common guidelines use a timeframe of 3-4 weeks postoperatively [22,23].

A recent study was able to identify a naturally occurring CRP peak on the third postoperative day after endoprosthetic joint replacement, independently of an infectious complication. The occurrence of a second peak was not considered in detail in this study [24].

One of the major factors contributing to CRP kinetics is the surgical approach. Iorio et al. compared the direct anterior approach (DAA) and direct lateral approach (DLA) and found no correlation between invasiveness (minimally invasive DAA) and CRP levels [25]. In our level-I certified endoprosthesis center in Germany (EPZmax), predominantly anterolateral (ALA) and posterior (PA) approaches are used for primary hip arthroplasty. The present study aimed to record postoperative CRP kinetics after primary hip arthroplasty to define CRP-kinetics in non-infectious and infectious primary hip arthroplasties, and to characterize differences and predictors for an infectious complication. To investigate possible influences of the surgical approach, a comparison between ALA and PA was made.

\section{Materials and Methods}

\subsection{Patients}

We treated 732 patients with primary hip arthroplasty at a level-I certified endoprosthesis center in Germany (EPZmax) between 2016 to 2020. We reviewed these patients retrospectively and included 708 after applying inclusion and exclusion criteria, which are specified below (Supplementary Materials Figure S1). 
The study was approved by the local ethics committee (IRB number $23 / 4 / 20$, ethics committee of the University of Goettingen) and performed in accordance with the principles expressed in the Declaration of Helsinki. All study participants voluntarily attended the study and gave informed consent.

The collected data included age, sex, length of stay in hospital, day of operation, postoperative time in hospital, diagnosis, indication, type of prosthesis, site of operation, approach, indication, positioning, height, weight, BMI, duration of procedure, infection, revision. Additional serological parameters including $\mathrm{CRP}, \mathrm{WBC}$, hemoglobin $(\mathrm{Hb})$ and platelets were recorded.

Serum was collected in the morning, and on average every 2.43 ( \pm 0.92$)$ days. The sample collection rate did not differ between the non-infection and infection group (Supplementary Materials Figure S2). We did not impute CRP values. If revision surgery occurred, we stopped recording serum parameters on the revision day to not confound measurements. Otherwise, the final day of discharge reflected the last day of recorded CRP values.

For all patients, intravenous antibiotics were applied at induction (single shot cefazolin $2 \mathrm{~g}$ or $600 \mathrm{mg}$ clindamycin in case of penicillin allergy or vancomycin $1.6 \mathrm{~g}$ ). According to the hospital's standards, intraoperatively applied drains were removed on the second day. Wound inspection took place every other day.

All patients were divided into a "non-infection" and "infection" (acute early) group by the authors MPM, IJB and DS. In order to classify a patient to the "infection" cohort, the detection of an organism on a specimen during revision surgery or obvious signs of a purulent infection during revision surgery was necessary. Patients were also assigned into the "infection" cohort by a positive joint puncture result as described below. The indication for revision surgery was given by a standardized sterile joint puncture according to criteria by Izakovicova, Borens and Trampuz [26]. A PJI was defined as a cell count above 2000 or a proportion of more than 70 percent neutrophil granulocytes in the joint puncture [26]. Multiple aerobic and anaerobic tissue biopsies were cultured (at least five with incubations lasting for at least three weeks) during revision surgery. At the same time, histopathology was obtained according to the recommendations of the Centers for Disease Control (CDC) $[27,28]$. Only the immediate postoperative CRP course was evaluated. After the patient was dismissed from the hospital, no further CRP values were included.

\subsection{Inclusion Criteria}

All patients older than 18 years with a primary hip replacement were included. The selection of patients followed the OPS codes 5-820.0, 5-820.2**, 5-820.4** or 5-820.9 ${ }^{* *}$ means a sixth digit is needed for particular situations). The timeframe was from 1 January 2016 until 31 December 2020.

\subsection{Exclusion Criteria}

Patients with a polytrauma or other surgical interventions were excluded. A preoperatively diagnosed hip tumor or previous hip osteosynthesis (resulting in a Girdlestone situation) were likewise excluded (Supplementary Materials Figure S1). Every excluded revision surgery was either from a primary operation in another clinic or implanted before the beginning of our study (1 January 2016).

\subsection{Determination of Peak Value}

A postoperative peak was defined as a rise in CRP, which was preceded and followed by lower CRP values. A multiple linear regression analysis was performed to identify parameters determining the maximum CRP. A binary logistic regression for the binary variable "infection" was performed. 


\subsection{Postoperative Kinetics}

In non-infection patients, CRP data were plotted and normalized to the peak CRP. Day zero was set to the peak, which led to an exponential decay of CRP values. An approximation with one-phase and two-phase regression was tested. With a satisfactory approximation, we calculated the estimated relative CRP values for days 4 and 5 (49.67\% and $43.95 \%$ of maximum CRP, respectively). Subsequently, we extended the threshold by $15 \%$ (resulting in $72.30 \%$ and $64.67 \%$ on days 4 and 5) [29,30], and were able to determine values as "failure to decline" for days 4 and 5 . Resulting sensitivity and specificity were determined.

\subsection{Determination of Variables for the Events "Peak CRP" and "Infection"}

We aimed to define dependent variables for "maximum CRP", and performed a backward multiple linear regression (dependent variable: "maximum CRP"). For the single dichotomous variable "infection", a backward conditional binary logistic regression (dependent variable "infection") was performed. The combination of variables was assessed in a multinominal logistic regression, as referred to in detail in the results.

\subsection{Statistics}

We a priori estimated the necessary sample size ( $t$-test, point biserial correlation model) for a power of 0.95 (estimated effect size $\rho=0.15, \alpha=0.05$ ). The total necessary sample size was calculated to be $n=472$ (G*Power 3.1.9.7, Kiel, Germany). We tested for normal distribution of continuous variables with the Anderson-Darling test. Continuous variables were tested with Student's two-tailed $t$-test and the Mann-Whitney test. Categorial variables were analyzed with the Chi-square test and Fisher's exact test. Group differences in CRP kinetics were assessed with multiple $t$-tests, adjusted for multiple testing by the Holm-Sidak method.

Overall, mean \pm standard deviation was calculated. Statistical analysis was performed with GraphPad Prism 9.00 (GraphPad Software, San Diego, CA, USA), SPSS Statistics software version 27.0 (IBM SPSS Inc., Chicago, IL, USA) and R 4.0.5 (The R Foundation for Statistical Computing, Vienna, Austria). For the PCA analysis, the package PCAtools (2.4.0) was used. For the graphical summary of CRP kinetics, the packages ggplot2 (3.3.5), reshape2 (1.4.4) and tidyverse (1.3.1) were used. Significant differences are marked with asterisks $\left({ }^{* * * *} p<0.0001,{ }^{* * *} p<0.001,{ }^{* *} p<0.01,{ }^{*} p<0.05\right)$.

\section{Results}

\subsection{Cohort Characteristics: Non-Infection vs. Infection}

The operatively treated cohort consisted of 700 patients with no infection, and eight patients with an infection after primary hip arthroplasty. The gender distribution showed a slight imbalance with a predominantly male sex in the infection group (Fisher's exact, $p=0.026$, Table 1). Average postoperative days in hospital were significantly longer in the infection group (on average +15.56 days, Mann-Whitney, $p=0.044$, Table 1 ). The maximal postoperatively measured CRP was higher in the infection group (MannWhitney, $p=0.046$ ), while the mean postoperative CRP did not yield differences. Interestingly, the overall maximal CRP (pre- and postoperatively) appeared to be higher in the infection group (Mann-Whitney, $p=0.049$, Table 1). The existence of a second peak was more frequent in the infection group compared to the non-infection group (Fisher's exact, $p=0.013$, Table 1 ). 
Table 1. Group characteristics in the non-infection and infection cohort.

\begin{tabular}{|c|c|c|c|c|}
\hline Parameter & & $\begin{array}{l}\text { Non-Infection }( \pm S D) \\
(n=700)\end{array}$ & $\begin{array}{l}\text { Infection }( \pm S D) \\
(n=8)\end{array}$ & $p$-Value \\
\hline Age (years) & & $71.18( \pm 11.92)$ & $68.38( \pm 6.02)$ & 0.325 (n.s.) $^{1}$ \\
\hline \multirow{3}{*}{ Sex } & & & & $0.026\left(^{*}\right)^{2}$ \\
\hline & Male & $44.86 \%$ & $87.5 \%$ & \\
\hline & Female & $55.14 \%$ & $12.5 \%$ & \\
\hline $\operatorname{BMI}\left(\mathrm{kg} / \mathrm{m}^{2}\right)$ & & $27.08( \pm 5.40)$ & $27.57( \pm 4.29)$ & 0.382 (n.s.) ${ }^{1}$ \\
\hline Days until surgery & & $1.66( \pm 3.19)$ & $3.38( \pm 5.01)$ & 0.237 (n.s.) $^{1}$ \\
\hline Days in hospital (total) & & $11.94( \pm 5.67)$ & $29.25( \pm 22.89)$ & 0.053 (n.s.) $^{1}$ \\
\hline Days in hospital (postop) & & $10.30( \pm 4.25)$ & $25.86( \pm 20.95)$ & $0.044\left(^{*}\right)^{1}$ \\
\hline Time operation (min) & & $106.04( \pm 37.65)$ & $117.8( \pm 53.96)$ & 0.655 (n.s.) $^{1}$ \\
\hline Preoperative CRP (mean) & & $13.07( \pm 25.90)$ & $23.24( \pm 41.99)$ & 0.806 (n.s.) ${ }^{1}$ \\
\hline Preoperative CRP (max) & & $14.17( \pm 28.30)$ & $29.49( \pm 58.57)$ & 0.821 (n.s.) $^{1}$ \\
\hline Postoperative CRP (max) & & $97.60( \pm 60.95)$ & $143.38( \pm 72.31)$ & $0.046\left(^{*}\right)^{1}$ \\
\hline Postoperative CRP (mean) & & $65.89( \pm 37.57)$ & $82.92( \pm 42.20)$ & 0.200 (n.s.) $^{1}$ \\
\hline CRP overall (max) & & $98.06( \pm 60.99)$ & $143.38( \pm 72.31)$ & $0.049\left(^{*}\right)^{1}$ \\
\hline CRP overall (mean) & & $52.41( \pm 33.10)$ & $73.40( \pm 41.77)$ & 0.109 (n.s.) $^{1}$ \\
\hline Average day of 2 nd CRP peak & & $9.46( \pm 3.15)$ & $8.25( \pm 3.20)$ & 0.516 (n.s.) ${ }^{1}$ \\
\hline Preoperative WBC (mean) & & $8.45( \pm 3.89)$ & $7.59( \pm 2.55)$ & 0.390 (n.s.) $^{1}$ \\
\hline Postoperative WBC (max) & & $10.41( \pm 5.11)$ & $11.01( \pm 5.30)$ & 0.829 (n.s.) $^{1}$ \\
\hline WBC overall (max) & & $10.93( \pm 5.54)$ & $11.28( \pm 5.24)$ & 0.923 (n.s.) $^{1}$ \\
\hline Preoperative $\mathrm{Hb}$ (mean) & & $13.43( \pm 2.06)$ & $12.32( \pm 1.89)$ & 0.105 (n.s.) $^{1}$ \\
\hline Postoperative $\mathrm{Hb}$ (max) & & $11.07( \pm 3.00)$ & $10.05( \pm 0.86)$ & 0.130 (n.s.) $^{1}$ \\
\hline $\mathrm{Hb}$ overall (max) & & $13.71( \pm 3.04)$ & $12.4( \pm 1.71)$ & 0.103 (n.s.) $^{1}$ \\
\hline \multirow[t]{7}{*}{ Approach } & & & & 0.151 (n.s.) $^{3}$ \\
\hline & $\begin{array}{l}\text { Anterolateral } \\
\text { (Watson-Jones) }\end{array}$ & $50.86 \%$ & $25 \%$ & \\
\hline & posterior & $40.71 \%$ & $50 \%$ & \\
\hline & Lateral (Bauer) & $4.71 \%$ & $25 \%$ & \\
\hline & $\begin{array}{l}\text { Anterior intrapelvic } \\
\text { (STOPPA) }\end{array}$ & $0 \%$ & $0 \%$ & \\
\hline & Kocher-Langenbeck & $0.14 \%$ & $0 \%$ & \\
\hline & anterior & $0.29 \%$ & $0 \%$ & \\
\hline \multirow[t]{3}{*}{ Emergency-Ind? } & & & & 0.724 (n.s.) ${ }^{2}$ \\
\hline & Yes & $33.00 \%$ & $37.50 \%$ & \\
\hline & No & $67.00 \%$ & $62.50 \%$ & \\
\hline \multirow[t]{3}{*}{ Indication } & & & & 1.000 (n.s.) ${ }^{2}$ \\
\hline & Trauma & $34.29 \%$ & $37.5 \%$ & \\
\hline & Other & $65.71 \%$ & $62.5 \%$ & \\
\hline \multirow[t]{3}{*}{ 2nd CRP peak } & & & & $0.013\left({ }^{*}\right)^{2}$ \\
\hline & yes & $12.86 \%$ & $50 \%$ & \\
\hline & no & $87.14 \%$ & $50 \%$ & \\
\hline
\end{tabular}

\footnotetext{
${ }^{1}$ Mann-Whitney test, ${ }^{2}$ Fisher's exact test, ${ }^{3}$ Chi-square test., ${ }^{*} p<0.05$, significant differences are highlighted in bold.
}

\subsection{Cohort Characteristics: Anterolateral vs. Posterior Approach}

While the patients operated on via a posterior approach were younger (Mann-Whitney, $p<0.0001$, Table 2), and male (Chi-square $p=0.026$, Table 2), their BMI was higher (MannWhitney, $p<0.0001$ ) and their preoperative time in hospital was longer (Mann-Whitney, $p<0.0001$, Table 2). Patients operated on via a posterior approach were hospitalized 1.66 days longer (Mann-Whitney, $p=0.002$, Table 2), which was in part due to a prolonged postoperative stay (Mann-Whitney, $p=0.022$, Table 2). The maximal postoperative CRP and overall CRP and the pre- and postoperatively measured WBC, were lower (CRP max and overall Mann-Whitney, $p=0.009$, respectively, WBC pre- Mann-Whitney, $p=0.001$ and WBC postoperatively 0.002, Table 2), as well as the overall WBC (Mann-Whitney, $p<0.0001$, Table 2). 
Table 2. Group characteristics in the non-infection group: anterolateral vs. posterior approach.

\begin{tabular}{|c|c|c|c|}
\hline Parameter & Anterolateral $( \pm \mathrm{SD})(n=358)$ & Posterior $( \pm \mathrm{SD})(n=289)$ & $p$-Value \\
\hline Age (years) & $73.74( \pm 11.69)$ & $67.51( \pm 11.46)$ & $\left.<0.0001{ }^{(* * * *)}\right)^{1}$ (n.s.) $)^{1}$ \\
\hline Sex & & & $0.026(*)^{2}$ \\
\hline Male & $42.46 \%$ & $49.66 \%$ & \\
\hline Female & $57.54 \%$ & $50.34 \%$ & \\
\hline $\operatorname{BMI}\left(\mathrm{kg} / \mathrm{m}^{2}\right)$ & $25.92( \pm 4.58)$ & $28.63( \pm 6.16)$ & $<0.0001\left(^{* * * *}\right)^{1}$ \\
\hline Days until surgery & $1.43( \pm 2.42)$ & $2.10( \pm 4.17)$ & $<0.0001(* * * *))^{1}$ \\
\hline Days in hospital (total) & $11.64( \pm 5.82)$ & $13.03( \pm 7.02)$ & $0.002(* *)^{1}$ \\
\hline Days in hospital (postop) & $10.25( \pm 4.94)$ & $10.93( \pm 4.98)$ & $0.022(*)^{1}$ \\
\hline Time operation (min) & $105.69( \pm 36.43)$ & $108.23( \pm 41.18)$ & 0.391 (n.s.) $^{1}$ \\
\hline Preoperative CRP (mean) & $13.89( \pm 25.35)$ & $11.95( \pm 25.22)$ & 0.371 (n.s.) $^{1}$ \\
\hline Preoperative CRP (max) & $15.30( \pm 28.28)$ & $13.99( \pm 28.33)$ & 0.459 (n.s.) $^{1}$ \\
\hline Postoperative CRP (max) & $102.47( \pm 59.63)$ & $93.90( \pm 63.91)$ & $0.009(* *)^{1}$ \\
\hline Postoperative CRP (mean) & $67.26( \pm 35.59)$ & $65.34( \pm 41.01)$ & 0.090 (n.s.) $^{1}$ \\
\hline CRP overall (max) & $102.77( \pm 59.47)$ & $94.42( \pm 64.15)$ & $0.009(* *)^{1}$ \\
\hline CRP overall (mean) & $53.84( \pm 31.40)$ & $51.68( \pm 36.18)$ & 0.072 (n.s.) $^{1}$ \\
\hline Average day of 2nd peak & $9.45( \pm 3.06)$ & $9.39( \pm 3.37)$ & 0.749 (n.s.) $^{1}$ \\
\hline Preoperative WBC (mean) & $8.88( \pm 4.70)$ & $7.80( \pm 2.52)$ & $0.001(* *)^{1}$ \\
\hline Postoperative WBC (max) & $10.55( \pm 4.10)$ & $10.32( \pm 6.43)$ & $0.002(* *)^{1}$ \\
\hline WBC overall (max) & $11.18( \pm 4.99)$ & $10.64( \pm 6.45)$ & $<0.0001(* * * *) 1$ \\
\hline Preoperative $\mathrm{Hb}$ (mean) & $13.43( \pm 1.89)$ & $13.45( \pm 2.35)$ & 0.638 (n.s.) $^{1}$ \\
\hline Postoperative $\mathrm{Hb}$ (max) & $10.93( \pm 2.69)$ & $11.29( \pm 3.44)$ & 0.125 (n.s.) $^{1}$ \\
\hline $\mathrm{Hb}$ overall $(\max )$ & $13.64( \pm 2.64)$ & $13.85( \pm 3.60)$ & 0.910 (n.s.) $^{1}$ \\
\hline Infection & & & 0.415 (n.s.) ${ }^{3}$ \\
\hline Yes & $0.56 \%$ & $1.38 \%$ & \\
\hline No & $99.44 \%$ & $98.62 \%$ & \\
\hline \multirow[t]{3}{*}{2 nd peak } & & & 0.389 (n.s.) ${ }^{2}$ \\
\hline & yes & $14.80 \%$ & $12.46 \%$ \\
\hline & no & $85.20 \%$ & $87.54 \%$ \\
\hline
\end{tabular}

${ }^{1}$ Mann-Whitney test, ${ }^{2}$ Chi-Quadrat test ${ }^{3}$ Fisher's exact test. ${ }^{* * *} p<0.0001,{ }^{* * *} p<0.001,{ }^{* *} p<0.01,{ }^{*} p<0.05$, significant differences are highlighted in bold.

\subsection{Prediction of Postoperative CRP Kinetics}

The comparative kinetics of the pre- and postoperative CRP course in non-infectious and infectious patients is depicted in Figure 1A. On days 11 and 14, the infection group showed significantly higher CRP values compared to the non-infection group $\left(\mathrm{p}_{\mathrm{adj}}=0.004\right.$, and $p_{\text {adj }}=0.002$, respectively, two-stage step-up of Benjamini, Krieger and Yekutieli with FDR correction, Figure 1A), while the two approaches (anterolateral vs. posterior) did not differ significantly at any point in time (Figure 1B). Comparing the indications (trauma vs. non-trauma), significant differences occurred on day -1 and day 1 ( $p_{\text {adj }} \leq 0.0001$, respectively, two-stage step-up of Benjamini, Krieger and Yekutieli with FDR correction, Figure 1C).

In order to predict the (postoperative) regularly expected decline of CRP, we assumed a one-phase decay after a peak CRP value was reached. Setting the (individually determined) maximum CRP as day zero and 100\%, the predicted one-phase decay is reached in the non-infection group and infection group with a satisfying accuracy $\left(R^{2}=0.72\right.$ and $R^{2}=0.83$, respectively). The calculated formula for the one-phase decay was:

$$
f(x)=0.7235 \times e^{-0.2883 \times x}+0.2683
$$

for $f(x)=\%$ of CRP peak and $x=$ days after maximum CRP (Figure 1D). 

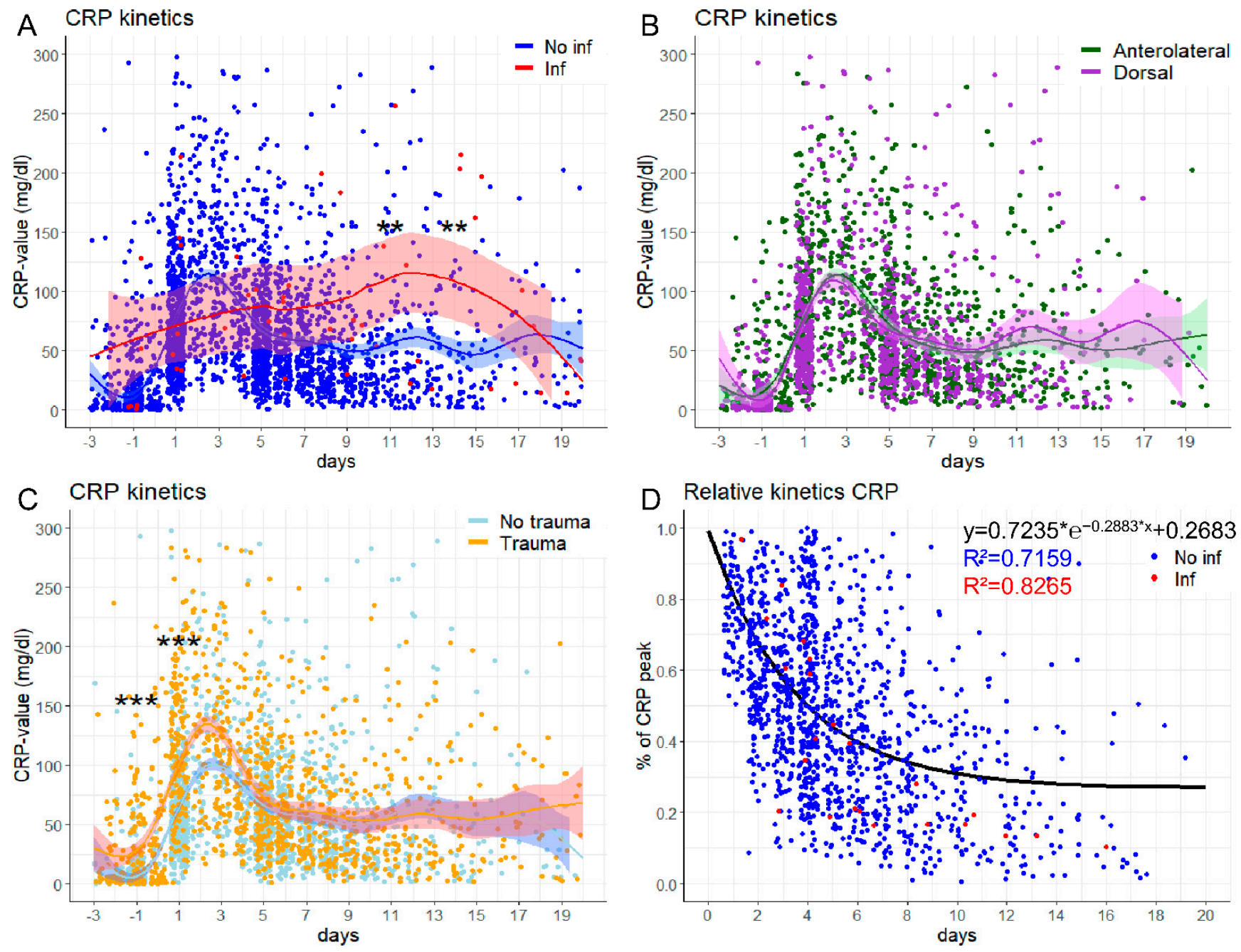

Figure 1. The postoperative CRP course in patients with and without an infection. (A) Comparing the absolute CRP course in patients with (red) and without (blue) an infection demonstrates a significant difference on days 11 and 14 (FDR day 11: q-value $=0.0037$, FDR day 14: q-value $=0.0019)$. $($ B) Comparing the anterolateral (green) with the posterior (orchid) approach, no statistically significant differences regarding daily CRP can be detected. (C) Comparing traumatic and nontraumatic hip arthroplasty, traumatic have significantly higher CRP values on days -1 (FDR q-value $<0.0001$ ) and 1 (FDR q-value < 0.0001). (D) The relative CRP kinetics after a maximum CRP value follows a one-phase exponential decay and can be predicted in a sufficient manner ( $\mathrm{R}^{2}$ no infection: $0.716, \mathrm{R}^{2}$ with an infection: 0.827$) .{ }^{* *} p<0.001,{ }^{* *} p<0.01$. * means multiplication.

\subsection{Prediction of an Infection: Single Variables}

At first, we aimed to predict a PJI by using all assessed parameters in an unbiased principal component analysis (PCA). With all these variables in (unweighted) combination, just an unsatisfying differentiation could be made (Supplementary Materials Figure S3A,B), so we proceeded with the stepwise validation of single parameters.

\subsubsection{Maximum CRP}

In order to identify variables most predictive of an infectious complication, we first identified parameters for the maximum CRP, since the maximum CRP was able to differentiate among both the non-infection vs. infection and anterolateral vs. posterior groups. We characterized its predictors performing a multiple linear regression (dependent variable "maximum CRP", Table 3). In a satisfactory approximation, we constituted six significant parameters determining the maximum CRP. Out of these, the highest weight was attributed to the preoperative mean CRP $(\beta=0.272$, Table 3$)$, followed by the occurrence of a second 
peak ( $\beta=0.216$, Table 3$)$ and the age of the patient $(\beta=0.161$, Table 3$)$. However, applying the maximum CRP value for detection of an infection yielded a maximum sensitivity of $75 \%$ and a specificity of $56.86 \%$, respectively (AUC: 0.7028 , Figure $2 \mathrm{~A}, \mathrm{~B}$ ).

Table 3. Multiple linear regression with "maximum CRP" as the dependent variable ("backward", $R^{2}=0.284$ ).

\begin{tabular}{lll}
\hline Independent Variable & Standardized Coefficients $\beta$ & $p$-Value \\
\hline CRP (preop mean) & 0.272 & $0.000\left(^{* * * *}\right)$ \\
Appearance of a 2nd peak & 0.216 & $0.000\left(^{* * * *}\right)$ \\
Age & 0.161 & $0.001\left(^{* *}\right)$ \\
Postoperative days in hospital & 0.126 & $0.008\left(^{* *}\right)$ \\
Failure to decline on day 5 & -0.125 & $0.006\left(^{* *}\right)$ \\
Gender $(1=\mathrm{m})$ & -0.110 & $0.015\left(^{* *}\right)$ \\
${ }^{* * * *} p<0.0001,{ }^{* *} p<0.01,{ }^{*} p<0.05$. & &
\end{tabular}

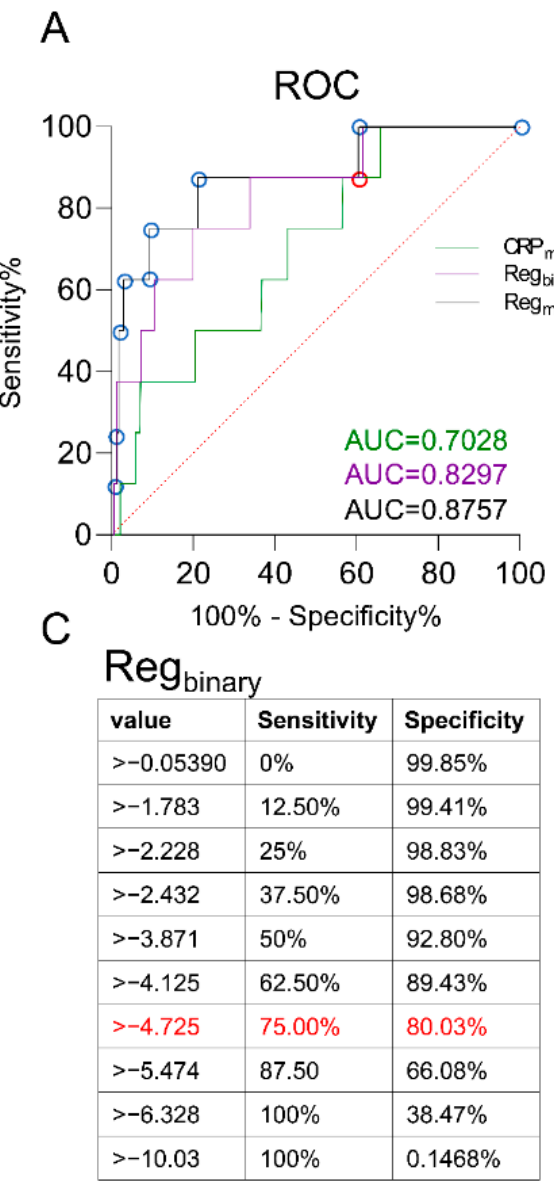

B

CRP max
\begin{tabular}{|l|l|l|}
\hline value & Sensitivity & Specificity \\
\hline$>379.9$ & $0.00 \%$ & 99.86 \\
\hline$>254.2$ & $12.50 \%$ & 97.86 \\
\hline$>213.4$ & $25.00 \%$ & 94.14 \\
\hline$>202.7$ & 37.5 & 92.86 \\
\hline$>139.1$ & $50 \%$ & 79.57 \\
\hline$>104.2$ & $62.5 \%$ & 63.14 \\
\hline$>91.20$ & $75 \%$ & 56.86 \\
\hline$>74.25$ & $87.50 \%$ & 43.29 \\
\hline$>63.35$ & $100.00 \%$ & $34.14 \%$ \\
\hline$>0.415$ & $100 \%$ & $0.2857 \%$ \\
\hline
\end{tabular}

D

$\operatorname{Reg}_{\text {multi }}$
\begin{tabular}{|l|l|l|}
\hline value & Sensitivity & Specificity \\
\hline$>-0.5561$ & $0.00 \%$ & $99.56 \%$ \\
\hline$>-2.936$ & $12.50 \%$ & $98.53 \%$ \\
\hline$>-4.029$ & $25.00 \%$ & $98.24 \%$ \\
\hline$>-5.074$ & $50.00 \%$ & $97.06 \%$ \\
\hline$>-6.603$ & $62.50 \%$ & $90.60 \%$ \\
\hline$>-8.565$ & $75.00 \%$ & $78.85 \%$ \\
\hline$>-8.566$ & $87.50 \%$ & $78.85 \%$ \\
\hline$>-26.50$ & $87.50 \%$ & $39.50 \%$ \\
\hline$>-26.52$ & $100.00 \%$ & $39.50 \%$ \\
\hline$>-31.53$ & $100.00 \%$ & $0.1468 \%$ \\
\hline
\end{tabular}

Figure 2. ROC analysis of a single value and two formulas for the prediction of an infection. (A) The ROC analysis shows the different performance of three infection prediction models. (B) The single parameter "CRP max" is able to predict an infection with a sensitivity of $75 \%$ and a specificity of $56.86 \%$, if the cut-off is set above $91.20 \mathrm{mg} / \mathrm{L}$ (AUC: 0.7028). (C) A binary logistic regression with a cut-off above -4.725 leads to a sensitivity and specificity of $75 \%$ and $80.03 \%$, respectively (AUC: 0.8297). (D) A multinominal logistic regression consisting of the five most important parameters leads to the development of an equation with the ability to predict an infectious complication with a sensitivity of $87.5 \%$ and an accompanying specificity of $78.85 \%$, if the cut-off is set to $>-8.566$ (AUC: 0.8757). The mentioned "best" values are marked in red. 


\subsubsection{Second Peak, Failure to Decline}

Next, we assessed the appearance of a second peak ("rise in CRP, which was preceded and followed by lower CRP values"), which was highly predictive in acetabular surgery [29] and spine surgery [30]. The sensitivity and specificity of a second peak were at a low $12.50 \%$ and $87.57 \%$, respectively.

A failure to decline could be calculated for days 4 and 5 (for details see methods). The sensitivity and specificity of a "failure to decline" on day 4 were 66.67 and $69.12 \%$, respectively, and for day 5, 50\% and $63.50 \%$, respectively. Taken together, the use of a single variable to predict an infection did not lead to satisfactory predictive parameters.

\subsection{Prediction of an Infection: Binary Logistic Regression}

Subsequently, we combined multiple parameters. To determine the probability of an infectious complication, we performed a binary logistic regression with the dependent variable "infection" (backward conditional), and created a model with mediocre approximation (Cox and Snell $R^{2}=0.020$, Nagelkerke $R^{2}=0.218$, Table 4). In the model, just two out of the six included parameters showed a significant predictive value, preoperative mean CRP $(p=0.035$, Table 4$)$ and maximum CRP (day, $p=0.008$, Table 4$)$. The formula was as follows:

$$
\begin{gathered}
f(x)=-2.447 * 2 \text { nd peak }+0.004 \times \mathrm{CRP}_{\max }+0.029 \times \mathrm{BMI}-1.504 \times \text { gender } \\
+0.381 \times \mathrm{CRP}_{\max , \text { day }}+0.024 \times \mathrm{CRP}_{\text {preop }(\text { average })}-5.85
\end{gathered}
$$

Table 4. Binary logistic regression with "infection" as the dependent variable ("backward: conditional", Cox and Snell $R^{2}=0.020$, Nagelkerke $R^{2}=0.218$ ).

\begin{tabular}{lll}
\hline Covariate Variable & Exp & $p$-Value \\
\hline Second peak & 0.087 & 0.186 (n.s.) \\
CRP max & 1.004 & 0.410 (n.s.) \\
BMI & 1.030 & 0.764 (n.s.) \\
Sex & 0.222 & 0.217 (n.s.) \\
CRP (preop mean) & 1.024 & $\mathbf{0 . 0 3 5}\left({ }^{*}\right)$ \\
CRP (max day) & 1.464 & $\left.\mathbf{0 . 0 0 8}{ }^{* *}\right)$ \\
${ }^{* *} p<0.01,{ }^{*} p<0.05$. & &
\end{tabular}

For 2 nd peak $(1=$ yes, $0=$ no $)$, gender $(1=$ male, $2=$ female $)$.

This leads to a dynamic sensitivity and specificity model, with an exemplary sensitivity of $75 \%$ and specificity of $80.03 \%$, if the cut-off $>-4.725$ is chosen, and an AUC of 0.8297 (Figure 2A,C).

\subsection{Prediction of an Infection: Multinominal Logistic Regression}

In order to improve the mathematical prediction of an emerging infection, we performed a multinominal logistic regression with five variables: approach (1-6, ordinal), preoperative mean CRP (numerical), day of maximum CRP (numerical), gender (dichotomous), and failure to decline on day 5 (dichotomous), leading to a dynamic sensitivity and specificity, depending on a specific cut-off. The obtained formula was:

$$
\begin{aligned}
f(x)= & 1.957 \times \text { approach }+0.0041 \times \mathrm{CRP}_{\text {preop mean }}+0.611 \times \mathrm{CRP}_{\text {max }, \text { day }} \\
& -18.57 \times \text { gender }+1.965 \times \text { failure to decline } \\
\text { day } 5 & +4.988
\end{aligned}
$$

For approach [1 = anterolateral (Watson-Jones), $2=$ posterior, $3=$ lateral (Bauer), $4=$ anterior intrapelvic (STOPPA), $5=$ Kocher-Langenbeck, $6=$ anterior $]$, gender $(1=$ male, 2 = female), failure to decline day $5(1=$ yes, $0=$ no $)$.

We depict the resulting ROC analysis with an area under the curve (AUC) of 0.8757 in Figure 2A,D. Exemplarily, setting a cut-off $>-8.566$ leads to a sensitivity of $87.5 \%$ to detect an infectious complication and an accompanying specificity of $78.85 \%$ to not miss an infection (Figure 2D). 


\subsection{Patients with Infections}

From the eight patients with a postoperative infection, four (50\%) suffered from an S. aureus infection. In just one patient, a second peak occurred, while two (25\%) showed a failure to decline (Table 5).

Table 5. Infectious complications occurred in eight patients.

\begin{tabular}{|c|c|c|c|c|c|c|c|}
\hline Pat. & Peak (Day) & Peak (mg/L) & Specimen & $\begin{array}{c}\text { 2nd CRP } \\
\text { Peak (Day) }\end{array}$ & $\begin{array}{l}\text { Failure to } \\
\text { Decline? }\end{array}$ & $\begin{array}{c}\text { Predicted CRP } \\
(\mathrm{mg} / \mathrm{L})\end{array}$ & $\begin{array}{c}\text { Actual CRP } \\
(\mathrm{mg} / \mathrm{L})\end{array}$ \\
\hline 1 & 11 & 256.4 & S. aureus & & $\mathrm{No}$ & 165.81 (day 4) & - \\
\hline 2 & 6 & 91.5 & S. aureus & & No & 59.17 (day 4) & - \\
\hline 3 & 6 & 105.1 & P. aeroginosa & & Yes & 67.96 (day 4) & 96.60 \\
\hline 4 & 6 & 63.4 & S. aureus & & No & 41.00 (day 4) & - \\
\hline 5 & 1 & 139.1 & S. aureus & & No & 89.95 (day 4) & 28.30 \\
\hline 6 & 5 & 74.6 & $\begin{array}{l}\text { Staphylococcus } \\
\text { saccharolyticus }\end{array}$ & & Yes & 53.93 (day 3) & 68.9 \\
\hline 7 & 14 & 203.2 & Enterococcus & 11 & No & 131.4 (day 4) & - \\
\hline 8 & 1 & 213.7 & P. aeroginosa & & No & 138.19 (day 4 ) & 129.50 \\
\hline
\end{tabular}

\section{Discussion}

The development of a PJI prolongs the inpatient stay considerably [31,32]. The maximum CRP and the presence of a second peak can be helpful for early infection detection [33-35]. This study was able to demonstrate the clinical applicability of two formulas forecasting a PJI. In addition, it was noticeable that the patients operated on via the posterior approach had a slightly longer length-of-stay, lower age and higher BMI than those operated on via the anterolateral approach.

Comparing patients without and with a postoperative PJI, we observed a longer postoperative stay in hospital in the patients with infection. On average, the patients with an acute early PJI stayed about 15.5 days longer than the patients without an infection. Data in the US shows an increase in the annual treatment costs of a PJI from 320 to 566 million USD/year from 2001 to 2009, which is projected to rise to USD 1.62 billion per year [12]. In Denmark, the cost per patient of a septic revision is EUR 27,059, compared to an aseptic revision at EUR 14,760 [36], with these differences illustrating how a complicating PJI after primary hip arthroplasty has an enormous economic impact.

An important parameter for the postoperative assessment of an infection is serum CRP values [37,38]. Contrary to the study by Akgün et al. [39], the present study was able to demonstrate the utility of individual CRP values for the detection of a PJI. We demonstrate differences between the patients without and with a PJI for the postoperative maximum CRP as well as for the overall CRP. Comparable results were found by Praz et al. This group analyzed serum CRP kinetics and found significantly higher serum CRP values in septic revision after primary hip and knee arthroplasties. The authors describe a sensitivity and specificity of $87.5 \%$ and $86.1 \%$, respectively, in detecting a PJI with serum CRP values (cut-off $9 \mathrm{mg} / \mathrm{L}$ ) [40]. When we used just a single value (maximum CRP), we were able to achieve a comparable sensitivity of $75 \%$, but lower specificity of $57 \%$. An explanation for the difference might have been that our PJI group was relatively small, while Praz et al. examined 42 revisions caused by a PJI. In addition, Sigmund et al. reported a relatively low sensitivity of $68 \%$, but a higher specificity of $87 \%$ for serum CRP values alone to predict a PJI (cut-off $10 \mathrm{mg} / \mathrm{L}$ ) in 177 patients undergoing hip or knee arthroplasty and revision surgery. In this study, 75 cases were classified as septic revisions, with serum CRP having an AUC of 0.78 [41]. Taking all these studies together, it should be noted that a maximum serum CRP value alone can be used to detect a PJI after hip arthroplasty. However, serum CRP values alone should not be used to detect a periprosthetic joint infection after hip arthroplasty, as mentioned by several guidelines and large patient cohorts [39,42-46]. A recent study on 177 patients confirmed the accuracy of serum CRP values in detecting a PJI, but concluded that CRP values alone can just be a suggestive criterion, while it should 
be complemented by more specific tests (i.e., synovial analysis) [41], which has also been found by another retrospective study with 215 patients [39].

Similarly, our study was able to demonstrate that a postoperative infection after treatment of an acetabular fracture can be detected by the maximum CRP and a second peak with a sensitivity of $83 \%$ and a specificity of $81 \%$ [29].

The previous remarks illustrate the importance of individual CRP values in the detection of a PJI. Another important aspect in laboratory diagnostics is CRP kinetics [38]. In order to use the dynamics of CRP development, we transformed the CRP values mathematically to investigate CRP kinetics in a relative manner from their maximum value. While the patients without an infection rarely revealed a second peak, it was more frequent in the patients with infection. The combination of a second peak and failure to decline seemed to be highly predictive in acetabular and spine surgery [29,30], while in this study, we could not confirm these results in primary hip arthroplasties. This may be due to the low numbers (four) in our cohort having a second CRP peak, out of eight patients with a PJI. Another reason might have been the traumatic kind of acetabular and vertebral fractures, which were less frequent in our analysis. Trauma itself is known to affect changes in CRP kinetics [47]. More than $60 \%$ of the indications for surgical treatment in our collective were of a nontraumatic origin.

To further elucidate the dynamic CRP changes, we made use of a logistic regression, which resulted in a sensitivity and specificity of $75 \%$ and $80.03 \%$, respectively (cut-off $>-4.725$, AUC of 0.8297) for predicting a hip PJI. To further improve the sensitivity, we utilized a multinomial logistic regression and achieved a sensitivity and specificity of $87.5 \%$ and $78.85 \%$, respectively (AUC: 0.8757 ). Potentially due to the higher complexity of the formula used, our analysis yielded significantly better results than comparative studies. Erdemli et al. achieved an AUC of 0.644 in a similar study [48]. They examined 88 patients who underwent revision arthroplasty, and compared a PJI-group $(n=36)$ to an aseptic-group $(n=52)$. In comparison to our study the authors examined a higher number of patients with infection. Schutz et al. [49] achieved a sensitivity of $65 \%$ and a specificity of $85 \%$ with two CRP values above their correlation, which was calculated with the help of a linear mixed model. Their 42 patients included hip arthroplasties as well as osteosynthetic treatments. The inclusion of osteosyntheses could have possibly influenced their analysis, while their overall number of patients was lower than ours [49]. Klim et al. similarly investigated the predictive value of CRP kinetics in the detection of a PJI in total hip or knee arthroplasties. Based on their ROC analysis, they concluded that a combined serum biomarker analysis had no benefit in the early diagnosis of a PJI [50]. Klim et al. examined 84 patients after total joint replacement of the knee or hip, of which a PJI was diagnosed in 55 cases. These authors examined significantly more PJIs than we did in our study. The contrary statement to our study could be due to the statistical methods or procedures of the authors. In contrast to our multinomial logistic regression, they performed a logistic regression with lasso regularization, and included knee arthroplasties in their study of 124 patients [50]. Schinsky et al. established that better predictive values can be achieved with the inclusion of a joint puncture in the synopsis of WBC in the aspirate, an elevated erythrocyte sedimentation rate (ESR) and CRP levels [51]. Taking their results into account, the predictive power of our formula could possibly be improved in the future by an additional joint puncture.

The question of "the optimal" approach for implantation of a primary hip joint endoprosthesis is still controversially discussed throughout the literature [52-59]. In our clinic, the anterolateral (Watson-Jones) and posterior (Moore) approaches [60,61] were predominantly used. Anatomical advantages and disadvantages of the two surgical approaches have been discussed extensively elsewhere $[58,59]$.

Of note, the patients who were operated on via the posterior approach stayed in our hospital slightly longer. This is in agreement with a study by Wang et al., showing a significantly shorter length of stay for the anterolateral approach ( $6.4 \pm 2.2$ days) compared 
to the posterior approach (9.2 \pm 3.1 days) in a study with 42 patients with an average age of 78.1 years [62].

We found no significant differences between the two approaches regarding the occurrence of a PJI. When comparing surgical approaches, recent studies were similarly unable to demonstrate a clear access-related disposition to infection. Shohat et al. showed that the direct anterior approach (DAA) to the hip does not increase the risk for a subsequent PJI [63]. No difference of DAA and direct lateral approach (DLA) regarding CRP values on days 1, 3 and 5 was found by Iorio et al., while the operative time was significantly shorter in DLA [25]. The surgeons included in this study used their individual favored approach, which may explain the lack of difference seen between the two approaches. This is comparable to our study, in which all surgeons used their individually preferred technique. Several studies have already shown that the access-related operating time is highly dependent upon the surgeon's experience [59]. Maezawa et al. reported a difference in CRP levels between the direct anterior approach (DAA) and posterior approach (PA) on day 1 after the operation, but not on day 4 in a study comprising 71 women [64]. As the number of overall cases in this study is rather small compared to our study and the influence of possible previous diseases is not considered, the reported significant difference on the first postoperative day could be a detection bias.

\section{Limitations}

By its nature, the low number of infections in primary hip arthroplasty restricts generalization of the results. We cannot exclude the possibility of infectious complications after the dismissal of patients; however, this seems unlikely due to the setting of the clinic and severity of a potential PJI. Nevertheless, some less virulent microorganisms may have led to the delayed development of symptoms and a delayed or late infection may have been missed, lowering the generalization of our results.

We did not assess further laboratory parameters like PCT and IL-6 on a regular basis, and therefore this has not been included in the present investigation. In future studies, these will be compared with CRP values and other traditional methods of infection detection prospectively. In addition, the results of this study will be tested prospectively in a different patient cohort.

\section{Conclusions}

The CRP kinetics after regular primary hip arthroplasty can be predicted after reaching the maximum CRP with an $R^{2}$ of 0.7159 . The peak CRP is directly affected by the preoperative mean CRP, the appearance of a second peak, age, and gender. An acute infection can be accurately predicted with a binary logistic regression resulting in a sensitivity of $75 \%$ and a specificity of $80 \%$. This is an indication of a reliable dynamic CRP development, which should be more focused on multiple than single values in the evaluation of a PJI. Single CRP values should not be used to diagnose a PJI or for the decision to perform a revision, as recommended by several guidelines, but complemented by more specific tests [44-46].

A more complex multinominal logistic regression leads to a sensitivity and specificity of $87.50 \%$ and $78.85 \%$, respectively.

Summarizing, a one-phase exponential decay can predict CRP kinetics, and an acute infectious complication can be reliably projected by using just five parameters. This easily applicable and budget-friendly formula represents a useful additional tool to further guide physicians to prognosticate the need for hip arthroplasty revision.

Supplementary Materials: The following are available online at https:/ / www.mdpi.com/article/10 $.3390 /$ jcm10214985/s1, Figure S1: Flowchart for inclusion of patients, Figure S2: Samples per day in hospital, Figure S3: PCA plots summarize all patients, weighed by all assessed parameters to distinguish infectious and non-infectious cohorts. 
Author Contributions: M.-P.M. and D.S. designed the study. I.J.B. performed all experimental procedures. Data analysis was carried out by I.J.B., M.-P.M. and D.S., M.-P.M. and D.S. wrote the manuscript. M.-P.M., I.J.B., A.K.M., M.H., K.J., J.H., T.H., W.L. and D.S. critically revised it for important intellectual content. All authors have approved the final version of the article, including the authorship list. All authors have read and agreed to the published version of the manuscript.

Funding: D.S. was funded by the Deutsche Forschungsgemeinschaft (DFG, German Research Foundation)-413501650. M.H. was funded by the Deutsche Forschungsgemeinschaft (DFG, German Research Foundation)-466023693.

Institutional Review Board Statement: The study was approved by the local ethics committee (IRB number 23/4/20, ethics committee of the University of Goettingen) and performed in accordance with the principles expressed in the Declaration of Helsinki.

Informed Consent Statement: Informed consent was obtained from all subjects involved in the study.

Data Availability Statement: Data available on request due to restrictions e.g., privacy or ethical.

Conflicts of Interest: The authors declare that they have no conflict of interest.

\section{References}

1. Statistisches Bundesamt. Gesundheit: Fallpauschalenbezogene Krankenhausstatistik (DRG-Statistik) Operationen und Prozeduren der vollstationären Patientinnen und Patienten in Krankenhäusern 2019; Statistisches Bundesamt: Wiesbaden, Germany, 2017.

2. Nowossadeck, E. Population aging and hospitalization for chronic disease in Germany. Dtsch. Arztebl. Int. 2012, 109, 151-157. [CrossRef]

3. Pilz, V.; Hanstein, T.; Skripitz, R. Projections of primary hip arthroplasty in Germany until 2040. Acta Orthop. 2018, 89, 308-313. [CrossRef] [PubMed]

4. Kamath, A.F.; Ong, K.L.; Lau, E.; Chan, V.; Vail, T.P.; Rubash, H.E.; Berry, D.J.; Bozic, K.J. Quantifying the Burden of Revision Total Joint Arthroplasty for Periprosthetic Infection. J. Arthroplasty 2015, 30, 1492-1497. [CrossRef]

5. Steinbrück, A.; Grimberg, A.W.; Elliott, J.; Melsheimer, O.; Jansson, V. Kurz- vs. Normalschaft bei zementfreier Hüfttotalendoprothese: Eine evidenzbasierte Register-Analyse zum mittelfristigen Überleben. Orthopade 2021, 50, 296-305. [CrossRef]

6. Gundtoft, P.H.; Pedersen, A.B.; Varnum, C.; Overgaard, S. Increased Mortality After Prosthetic Joint Infection in Primary THA. Clin. Orthop. Relat. Res. 2017, 475, 2623-2631. [CrossRef] [PubMed]

7. George, J.; Navale, S.M.; Nageeb, E.M.; Curtis, G.L.; Klika, A.K.; Barsoum, W.K.; Mont, M.A.; Higuera, C.A. Etiology of Aboveknee Amputations in the United States: Is Periprosthetic Joint Infection an Emerging Cause? Clin. Orthop. Relat. Res. 2018, 476, 1951-1960. [CrossRef] [PubMed]

8. Guren, E.; Figved, W.; Frihagen, F.; Watne, L.O.; Westberg, M. Prosthetic joint infection-a devastating complication of hemiarthroplasty for hip fracture. Acta Orthop. 2017, 88, 383-389. [CrossRef] [PubMed]

9. Zmistowski, B.; Karam, J.A.; Durinka, J.B.; Casper, D.S.; Parvizi, J. Periprosthetic joint infection increases the risk of one-year mortality. J. Bone Joint Surg. Am. 2013, 95, 2177-2184. [CrossRef] [PubMed]

10. Dragsted, C.; Aagaard, T.; Ohrt-Nissen, S.; Gehrchen, M.; Dahl, B. Mortality and health-related quality of life in patients surgically treated for spondylodiscitis. J. Orthop. Surg. 2017, 25, 2309499017716068. [CrossRef] [PubMed]

11. Chang, C.-H.; Lee, S.-H.; Lin, Y.-C.; Wang, Y.-C.; Chang, C.-J.; Hsieh, P.-H. Increased periprosthetic hip and knee infection projected from 2014 to 2035 in Taiwan. J. Infect. Public Health 2020, 13, 1768-1773. [CrossRef] [PubMed]

12. Kurtz, S.M.; Lau, E.; Watson, H.; Schmier, J.K.; Parvizi, J. Economic burden of periprosthetic joint infection in the United States. J. Arthroplasty 2012, 27, 61-65.e1. [CrossRef] [PubMed]

13. Vergison, L.; Schepens, A.; Liekens, K.; de Kesel, R.; van der Bracht, H.; Victor, J. Periprosthetic joint infection of a total hip arthroplasty with Candida parapsilosis. Int. J. Surg. Case Rep. 2020, 69, 72-75. [CrossRef]

14. Pellegrini, A.; Suardi, V.; Legnani, C. Classification and management options for prosthetic joint infection. Ann. Joint 2021. [CrossRef]

15. Rupp, M.; Kerschbaum, M.; Freigang, V.; Bärtl, S.; Baumann, F.; Trampuz, A.; Alt, V. PJI-TNM als neues Klassifikationssystem für Endoprotheseninfektionen: Eine Evaluation von 20 Fällen. Orthopade 2021, 50, 198-206. [CrossRef]

16. Compté, N.; Dumont, L.; Bron, D.; de Breucker, S.; Praet, J.-P.; Bautmans, I.; Pepersack, T. White blood cell counts in a geriatric hospitalized population: A poor diagnostic marker of infection. Exp. Gerontol. 2018, 114, 87-92. [CrossRef] [PubMed]

17. Deirmengian, G.K.; Zmistowski, B.; Jacovides, C.; O'Neil, J.; Parvizi, J. Leukocytosis is common after total hip and knee arthroplasty. Clin. Orthop. Relat. Res. 2011, 469, 3031-3036. [CrossRef] [PubMed]

18. Dobrindt, O.; Schmelzer, L.; Müller, M.; Perka, C.-F. Geringe Diagnostische Wertigkeit des CRP bei Low-Grade Infektionen von Hüftendoprothesen. In Deutscher Kongress für Orthopädie und Unfallchirurgie (DKOU 2014); German Medical Science GMS Publishing House: Moscow, Russia, 2014. 
19. Mitbreŭt, I.M.; Lavrishcheva, G.I.; Khorkin, N.N. Reparativnyŭ osteogenez pri perelome koster̆ pod vliianiem vozdeǐstviia v rannem periode travmy élektricheskogo polia UVCh v éksperimente i klinike. Vopr. Kurortol. Fizioter. Lech. Fiz. Kult. 1991, 6, 49-53.

20. Tsukayama, D.T.; Estrada, R.; Gustilo, R.B. Infection after total hip arthroplasty. A study of the treatment of one hundred and six infections. J. Bone Joint Surg. Am. 1996, 78, 512-523. [CrossRef]

21. Tande, A.J.; Patel, R. Prosthetic joint infection. Clin. Microbiol. Rev. 2014, 27, 302-345. [CrossRef] [PubMed]

22. Mühlhofer, H.M.L.; Gollwitzer, H.; Lenze, F.; Feihl, S.; Pohlig, F.; von Eisenhart-Rothe, R.; Schauwecker, J. Periprothetischer Infekt des Hüftgelenks: Klinisches Vorgehen. Orthopade 2015, 44, 357-365. [CrossRef] [PubMed]

23. Tornero, E.; Soriano, A. Importance of selection and duration of antibiotic regimen in prosthetic joint infections treated with debridement and implant retention-authors' response. J. Antimicrob. Chemother. 2016, 71, 3627. [CrossRef] [PubMed]

24. De Maio, F.; Fidone, G.; Caterini, A.; Gorgolini, G.; Petrungaro, L.; Farsetti, P. Monitoring of C-reactive protein level (CRP) and Erythrocyte sedimentation rate (ESR) after total hip and knee arthroplasty. J. Biol. Regul. Homeost. Agents 2020, 34, 63-68. [PubMed]

25. Iorio, R.; Viglietta, E.; Mazza, D.; Iannotti, F.; Nicolosi, I.; Carrozzo, A.; Speranza, A.; Ferretti, A. Do serum markers correlate with invasiveness of the procedure in THA? A prospective randomized study comparing direct anterior and lateral approaches. Orthop. Traumatol. Surg. Res. 2021, 102937. [CrossRef] [PubMed]

26. Izakovicova, P.; Borens, O.; Trampuz, A. Periprosthetic joint infection: Current concepts and outlook. EFORT Open Rev. 2019, 4, 482-494. [CrossRef] [PubMed]

27. Alexander, J.W.; Solomkin, J.S.; Edwards, M.J. Updated recommendations for control of surgical site infections. Ann. Surg. 2011, 253, 1082-1093. [CrossRef]

28. Mehta, J.A.; Sable, S.A.; Nagral, S. Updated recommendations for control of surgical site infections. Ann. Surg. 2015, 261 , e65. [CrossRef] [PubMed]

29. Saul, D.; Hünicke, P.; Böker, K.O.; Spering, C.; Maheshwari, A.K.; Acharya, M.; Lehmann, W. Predicting the disaster-The role of CRP in acetabular surgery. Clin. Biochem. 2021, 94, 48-55. [CrossRef] [PubMed]

30. Hoeller, S.; Roch, P.J.; Weiser, L.; Hubert, J.; Lehmann, W.; Saul, D. C-reactive protein in spinal surgery: More predictive than prehistoric. Eur. Spine J. 2021, 30, 1261-1269. [CrossRef] [PubMed]

31. Garfield, K.; Noble, S.; Lenguerrand, E.; Whitehouse, M.R.; Sayers, A.; Reed, M.R.; Blom, A.W. What are the inpatient and day case costs following primary total hip replacement of patients treated for prosthetic joint infection: A matched cohort study using linked data from the National Joint Registry and Hospital Episode Statistics. BMC Med. 2020, 18, 335. [CrossRef] [PubMed]

32. Kim, H.S.; Park, J.W.; Moon, S.Y.; Lee, Y.K.; Ha, Y.C.; Koo, K.H. Current and Future Burden of Periprosthetic Joint Infection from National Claim Database. J. Korean Med. Sci. 2020, 35, e410. [CrossRef] [PubMed]

33. Iannotti, F.; Prati, P.; Fidanza, A.; Iorio, R.; Ferretti, A.; Pèrez Prieto, D.; Kort, N.; Violante, B.; Pipino, G.; Schiavone Panni, A.; et al. Prevention of Periprosthetic Joint Infection (PJI): A Clinical Practice Protocol in High-Risk Patients. Trop. Med. Infect. Dis. 2020, 5, 186. [CrossRef] [PubMed]

34. Goswami, K.; Parvizi, J.; Maxwell Courtney, P. Current Recommendations for the Diagnosis of Acute and Chronic PJI for Hip and Knee-Cell Counts, Alpha-Defensin, Leukocyte Esterase, Next-generation Sequencing. Curr. Rev. Musculoskelet. Med. 2018, 11, 428-438. [CrossRef] [PubMed]

35. Wang, H.; Qin, L.; Wang, J.; Hu, N.; Huang, W. Combined serum and synovial C-reactive protein tests: A valuable adjunct to the diagnosis of chronic prosthetic joint infection. BMC Musculoskelet. Disord. 2021, 22, 670. [CrossRef] [PubMed]

36. Vanhegan, I.S.; Malik, A.K.; Jayakumar, P.; Ul Islam, S.; Haddad, F.S. A financial analysis of revision hip arthroplasty: The economic burden in relation to the national tariff. J. Bone Joint Surg. Br. 2012, 94, 619-623. [CrossRef] [PubMed]

37. Saleh, A.; George, J.; Faour, M.; Klika, A.K.; Higuera, C.A. Serum biomarkers in periprosthetic joint infections. Bone Joint Res. 2018, 7, 85-93. [CrossRef]

38. Lim, S.-J.; Choi, K.-H.; Lee, J.H.; Jung, J.Y.; Han, W.; Lee, B.H. Different Kinetics of Perioperative CRP after Hip Arthroplasty for Elderly Femoral Neck Fracture with Elevated Preoperative CRP. Biomed Res. Int. 2018, 2018, 2140105. [CrossRef] [PubMed]

39. Akgün, D.; Müller, M.; Perka, C.; Winkler, T. The serum level of C-reactive protein alone cannot be used for the diagnosis of prosthetic joint infections, especially in those caused by organisms of low virulence. Bone Joint J. 2018, 100, 1482-1486. [CrossRef]

40. Praz, C.; Gubbiotti, L.; Buia, G.; Chapus, V.; Dunet, J.; Grandhomme, F.; Michon, J.; Rochcongar, G.; Hulet, C. Value of the synovial C-reactive protein test in the diagnosis of total hip and knee periprosthetic joint infections: A case-control study. Orthop. Traumatol. Surg. Res. 2021, 107, 102903. [CrossRef]

41. Sigmund, I.K.; Holinka, J.; Staats, K.; Sevelda, F.; Lass, R.; Kubista, B.; Giurea, A.; Windhager, R. Inferior performance of established and novel serum inflammatory markers in diagnosing periprosthetic joint infections. Int. Orthop. 2021, 45, 837-846. [CrossRef] [PubMed]

42. Van den Kieboom, J.; Tirumala, V.; Xiong, L.; Klemt, C.; Kwon, Y.-M. Concomitant Hip and Knee Periprosthetic Joint Infection in Periprosthetic Fracture: Diagnostic Utility of Serum and Synovial Fluid Markers. J. Arthroplasty 2021, 36, 722-727. [CrossRef]

43. Kim, S.-J.; Cho, Y.J. Current Guideline for Diagnosis of Periprosthetic Joint Infection: A Review Article. Hip Pelvis 2021, $33,11-17$. [CrossRef] [PubMed]

44. McNally, M.; Sousa, R.; Wouthuyzen-Bakker, M.; Chen, A.F.; Soriano, A.; Vogely, H.C.; Clauss, M.; Higuera, C.A.; Trebše, R. The EBJIS definition of periprosthetic joint infection. Bone Joint J. 2021, 103, 18-25. [CrossRef] 
45. Tubb, C.C.; Polkowksi, G.G.; Krause, B. Diagnosis and Prevention of Periprosthetic Joint Infections. J. Am. Acad. Orthop. Surg. 2020, 28, e340-e348. [CrossRef] [PubMed]

46. Berbari, E.; Mabry, T.; Tsaras, G.; Spangehl, M.; Erwin, P.J.; Murad, M.H.; Steckelberg, J.; Osmon, D. Inflammatory blood laboratory levels as markers of prosthetic joint infection: A systematic review and meta-analysis. J. Bone Joint Surg. Am. 2010, 92, 2102-2109. [CrossRef] [PubMed]

47. Gołąbek-Dropiewska, K.; Pawłowska, J.; Witkowski, J.; Lasek, J.; Marks, W.; Stasiak, M.; Jaskólski, D.; Kawecka, A.; Łuczkiewicz, P.; Baczkowski, B. Analysis of selected pro- and anti-inflammatory cytokines in patients with multiple injuries in the early period after trauma. Cent. Eur. J. Immunol. 2018, 43, 42-49. [CrossRef] [PubMed]

48. Erdemli, B.; Özbek, E.A.; Başarir, K.; Karahan, Z.C.; Öcal, D.; Biriken, D. Proinflammatory biomarkers' level and functional genetic polymorphisms in periprosthetic joint infection. Acta Orthop. Traumatol. Turc. 2018, 52, 143-147. [CrossRef] [PubMed]

49. Schutz, R.; Boukebous, B.; Boutroux, P.; Guillon, P. C-reactive protein levels for early detection of early postoperative complications after proximal femoral fracture surgery. Eur. J. Orthop. Surg. Traumatol. 2018, 28, 907-913. [CrossRef]

50. Klim, S.M.; Amerstorfer, F.; Glehr, G.; Hauer, G.; Smolle, M.A.; Leitner, L.; Leithner, A.; Glehr, M. Combined serum biomarker analysis shows no benefit in the diagnosis of periprosthetic joint infection. Int. Orthop. 2020, 44, 2515-2520. [CrossRef]

51. Schinsky, M.F.; Della Valle, C.J.; Sporer, S.M.; Paprosky, W.G. Perioperative testing for joint infection in patients undergoing revision total hip arthroplasty. J. Bone Joint Surg. Am. 2008, 90, 1869-1875. [CrossRef] [PubMed]

52. Cheng, T.E.; Wallis, J.A.; Taylor, N.F.; Holden, C.T.; Marks, P.; Smith, C.L.; Armstrong, M.S.; Singh, P.J. A Prospective Randomized Clinical Trial in Total Hip Arthroplasty-Comparing Early Results between the Direct Anterior Approach and the Posterior Approach. J. Arthroplasty 2017, 32, 883-890. [CrossRef] [PubMed]

53. Higgins, B.T.; Barlow, D.R.; Heagerty, N.E.; Lin, T.J. Anterior vs. posterior approach for total hip arthroplasty, a systematic review and meta-analysis. J. Arthroplasty 2015, 30, 419-434. [CrossRef] [PubMed]

54. Hoskins, W.; Bingham, R.; Lorimer, M.; Hatton, A.; de Steiger, R.N. Early Rate of Revision of Total Hip Arthroplasty Related to Surgical Approach: An Analysis of 122,345 Primary Total Hip Arthroplasties. J. Bone Joint Surg. Am. 2020, 102, $1874-1882$. [CrossRef]

55. Moerenhout, K.; Derome, P.; Laflamme, G.Y.; Leduc, S.; Gaspard, H.S.; Benoit, B. Direct anterior versus posterior approach for total hip arthroplasty: A multicentre, prospective, randomized clinical trial. Can. J. Surg. 2020, 63, E412-E417. [CrossRef]

56. Petis, S.; Howard, J.L.; Lanting, B.L.; Vasarhelyi, E.M. Surgical approach in primary total hip arthroplasty: Anatomy, technique and clinical outcomes. Can. J. Surg. 2015, 58, 128-139. [CrossRef] [PubMed]

57. Putananon, C.; Tuchinda, H.; Arirachakaran, A.; Wongsak, S.; Narinsorasak, T.; Kongtharvonskul, J. Comparison of direct anterior, lateral, posterior and posterior-2 approaches in total hip arthroplasty: Network meta-analysis. Eur. J. Orthop. Surg. Traumatol. 2018, 28, 255-267. [CrossRef] [PubMed]

58. Roth, A.; Goralski, S.; Pempe, C. Zugangswege Hüftendoprothetik-Anterolateraler Zugang in Rückenlage. Orthopädie Unf. Up2date 2021, 16, 43-66. [CrossRef]

59. Nogler, M.; Thaler, M. Operative Zugangswege zur Hüfte beim älteren Menschen. Orthopade 2017, 46, 18-24. [CrossRef] [PubMed]

60. Claes, L.; Kirschner, P.; Perka, C.; Rudert, M. AE-Manual der Endoprothetik: Hüfte und Hüftrevision; Arbeitsgemeinschaft Endoprothetik: Berlin, Heidelberg, 2012; ISBN 978-3-642-14646-6.

61. Wagner, M.; Breusch, S.; Ewerbeck, V.; Aldinger, P.; Rudert, M.; Holzapfel, B.M.; Günther, K.-P.; Gotterbarm, T.; Kirschner, P.; Halder, A.M.; et al. Operation. In AE-Manual der Endoprothetik; Claes, L., Kirschner, P., Perka, C., Rudert, M., Eds.; Springer: Berlin/Heidelberg, Germany, 2012; pp. 161-323. ISBN 978-3-642-14645-9.

62. Wang, G.; Gu, G.; Li, D.; Sun, D.; Zhang, W.; Wang, T. Comparative study of anterolateral approach versus posterior approach for total hip replacement in the treatment of femoral neck fractures in elderly patients. Chin. J. Traumatol. 2010, 13, $234-239$.

63. Shohat, N.; Goswami, K.; Clarkson, S.; Chisari, E.; Breckenridge, L.; Gursay, D.; Tan, T.L.; Parvizi, J. Direct Anterior Approach to the Hip Does Not Increase the Risk for Subsequent Periprosthetic Joint Infection. J. Arthroplasty 2021, 36, 2038-2043. [CrossRef]

64. Maezawa, K.; Nozawa, M.; Gomi, M.; Sugimoto, M.; Maruyama, Y. Changes in serum creatine kinase and C-reactive protein after posterior and direct anterior approaches in total hip arthroplasty. Hip Int. 2020. [CrossRef] 